Review

\title{
Epstein-Barr Virus (EBV)-associated Gastric Carcinoma
}

Hisashi Iizasa ${ }^{1, \dagger}$, Asuka Nanbo ${ }^{2, \dagger}$, Jun Nishikawa ${ }^{3}$, Masahisa Jinushi ${ }^{4}$ and Hironori Yoshiyama ${ }^{4, *}$

1 Division of Stem Cell Biology, Institute for Genetic Medicine, Hokkaido University, N15 W7, Kitaku, Sapporo 060-0815, Japan; E-Mail:iizasah@igm.hokudai.ac.jp

2 Graduate School of Pharmaceutical Sciences, Hokkaido University, N12 W6, Kita-ku, Sapporo 0600812, Japan; E-Mail:nanboa@pharm.hokudai.ac.jp

3 Department of Gastroenterology and Hepatology, Yamaguchi University Graduate School of Medicine, Minami-Kogushi 1-1-1, Ube, Yamaguchi 755-8505, Japan; E-Mail: junnis@yamaguchi-u.ac.jp

4 Research Center for Infection-Associated Cancer, Institute for Genetic Medicine, Hokkaido University, N15 W7, Kita-ku, Sapporo 060-0815, Japan; E-Mails:jinushi@igm.hokudai.ac.jp (J.M.); hironori@igm.hokudai.ac.jp (H.Y.)

$\dagger$ These authors contributed equally to this work.

* Author to whom correspondence should be addressed; E-Mail: hironori@igm.hokudai.ac.jp; Tel.: +81-11-706-6073; Fax: +81-11-706-6071.

Received: 22 October 2012; in revised form: 22 November 2012 / Accepted: 26 November 2012 / Published: 29 November 2012

\begin{abstract}
The ubiquitous Epstein-Barr virus (EBV) is associated with several human tumors, which include lymphoid and epithelial malignancies. It is known that EBV persistently infects the memory B cell pool of healthy individuals by activating growth and survival signaling pathways that can contribute to B cell lymphomagenesis. Although the monoclonal proliferation of EBV-infected cells can be observed in epithelial tumors, such as nasopharyngeal carcinoma and EBV-associated gastric carcinoma, the precise role of EBV in the carcinogenic progress is not fully understood. This review features characteristics and current understanding of EBV-associated gastric carcinoma. EBVassociated gastric carcinoma comprises almost $10 \%$ of all gastric carcinoma cases and expresses restricted EBV latent genes (Latency I). Firstly, definition, epidemiology, and clinical features are discussed. Then, the route of infection and carcinogenic role of viral genes are presented. Of particular interest, the association with frequent genomic CpG
\end{abstract}


methylation and role of miRNA for carcinogenesis are topically discussed. Finally, the possibility of therapies targeting EBV-associated gastric carcinoma is proposed.

Keywords: EBV; Carcinogenesis; EBV-associated gastric carcinoma; Epithelial; CD21; Methylation; miRNA

\section{Introduction}

Epstein-Barr virus (EBV) is a ubiquitous human herpes virus with oncogenic activity. The EBV genome can be detected in malignancies of both lymphoid and epithelial cell origin, such as Burkitt's lymphoma (BL) and nasopharyngeal carcinoma (NPC) [1,2]. In 1990, EBV genomes were detected in gastric carcinomas using polymerase chain reaction [3] and in situ hybridization (ISH) for EBVencoded small ribonucleic acid 1 (EBER1). These findings indicated that EBV-associated gastric carcinomas (EBVaGC) comprise about $10 \%$ of all gastric carcinomas worldwide [4-6]. Since EBVaGC are monoclonal proliferations of a single cell persistently infected with EBV, EBV infection may be involved in the early stages of gastric carcinogenesis [7-9].

EBV spreads by the oral route [10].After primary infection, EBV establishes the lifelong virus carrier state, called latent infection, which expresses a limited set of viral genes required for viral episome maintenance, thereby conferring a survival advantage to the infected cell. BL, approximately half of the NPC, and EBVaGC belong to latency I, in which EBV nuclear antigen 1 (EBNA1), EBER1 and 2, and BamHI-A rightward transcripts (BART) are expressed. Latency II neoplasm includes the remaining NPC and Hodgkin's lymphoma (HL) and is characterized by the expression of latent membrane protein 1 (LMP1) in addition to latency I transcripts. Latency III neoplasms, typified by lymphomas observed in immunosuppressed patients, additionally expresses EBNA2, 3A, 3B, 3C, and LP. Three promoters ( $\mathrm{Cp}, \mathrm{Wp}$, and Qp) are utilized for EBNA transcription. The $\mathrm{Cp}$ - or Wp-initiated large transcript is differentially spliced into six EBNA mRNAs as observed in latency III cells, whereas Qp mediates selective expression of EBNA1 in Latency I or II cells [7]. The expression of latent genes is under a strict epigenetic regulation through DNA methylation. $\mathrm{Cp}$ and $\mathrm{Wp}$ are hypermethylated in latency I [11].

EBVaGC is a latency I neoplasm and expresses EBNA1, EBER, BART, and sometimes (40\%) latent membrane protein 2A (LMP2A) [9]. Since EBVaGC does not express EBNA2 and LMP1, which are important for B cell immortalization and transformation [2,7], preexisting abnormalities may exist in gastric epithelial cells [12]. Not only viral gene, but also the host cell DNA methylation has been frequently observed in EBVaGC [13-15]. Promoter hypermethylation of tumor-related genes is known to cause down-regulation of their gene expression [16]. Target gene silencing by viral micro RNAs (miRNAs) [17] has also been observed in EBV infected cells. Both mechanisms may influence the tumor progression of EBVaGC. 


\section{Definition, Epidemiology, and Clinical Features}

\subsection{Definition}

Almost $10 \%$ of the gastric carcinomas throughout the world are monoclonal proliferations of EBVcarrying tumor cells [4].A characteristic feature of EBVaGC is lymphoepithelioma-like carcinoma, which presents a diffuse-type histology with lymphoid infiltration. EBVaGC is defined by the presence of EBV in neoplastic cells. EBER1-in situ hybridization (ISH) is used to identify EBVaGC, because EBER1 is highly abundant (10 million copies per cell) in each infected cell. Typically, tumor cells, of which nuclei are positive for EBER1-ISH, are surrounded by lymphoid stroma (Figure 1). EBVaGC has distinct clinicopathological features, which predominantly arises in men and presents a generally diffuse histological type [18].

Figure 1. Lymphoepithelioma-like subtype of Epstein-Barr virus-associated gastric carcinomas (EBVaGC).A. Hematoxylin-Eosin Staining. B. EBV-encoded small ribonucleic acid-in situ hybridization (EBER1-ISH) demonstrates positive nuclei in the carcinoma cells, which are surrounded by infiltrating lymphocytes.
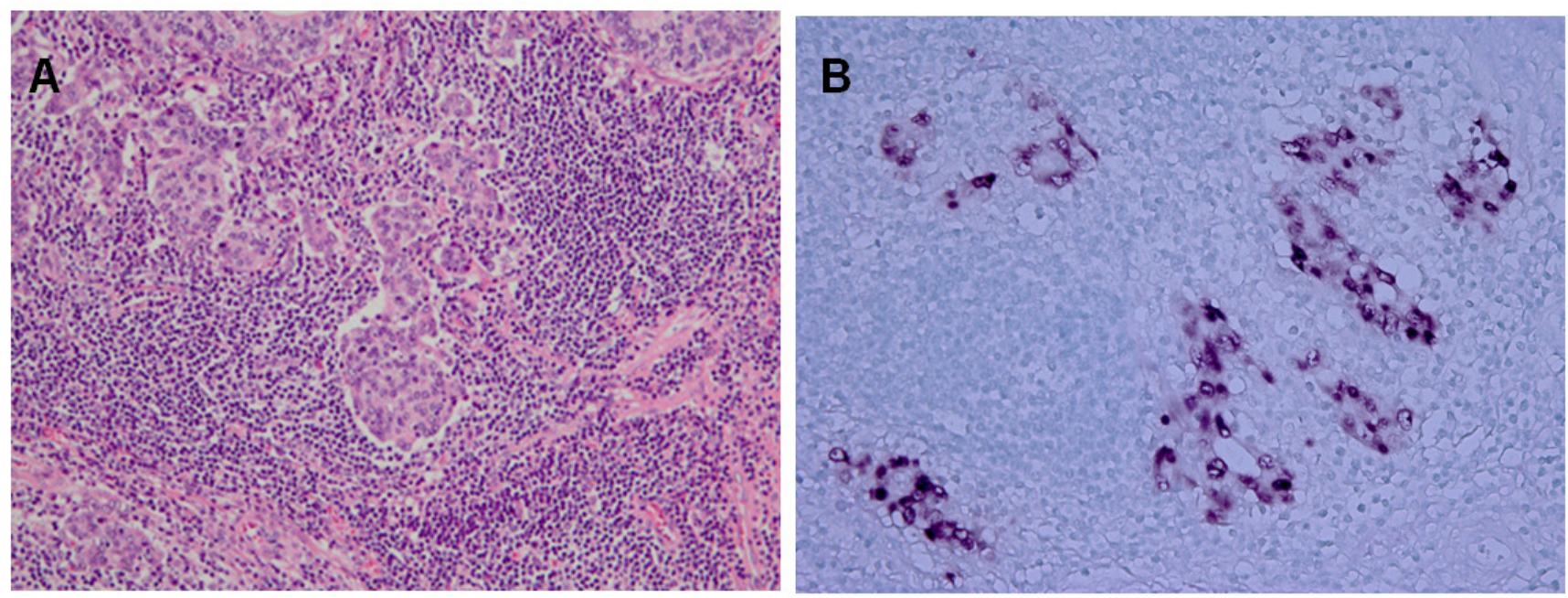

\subsection{Epidemiology}

Most studies did not show evident age dependence of EBVaGC frequency.Almost all studies have shown male predominance of EBVaGC, suggesting that risk from lifestyle or occupational factors may exist among males [19].An interview study in Japan showed that salty food intake and wood dust and/or iron filings exposure, which may induce mechanical injury to the gastric epithelia, are related to a higher EBVaGC risk [20].

In contrast to BL and NPC, which are endemic in Equatorial Africa and Southeast Asia, respectively, EBVaGC is a non-endemic disease distributed throughout the world [6]. However, there are some regional differences in the incidence of EBVaGC. The incidence of EBVaGC in all cases of gastric cancer is distributed from highest (16-18\%) in the USA and Germany to the lowest (4.3\%) in China $[6,21,22]$.A Japanese study investigated incidence of EBV-positive cases in all gastric cancers in 
several areas. The study indicated that $\mathrm{EBVaGC}$ prevalence was inversely related to the $\mathrm{GC}$ incidence [23]. Prognosis of EBVaGC is relatively favorable.

\subsection{Clinical Features}

The most useful modality for the diagnosis of gastric carcinoma is endoscopy. By endoscopy, EBVaGC appears as superficial depressed (or ulcerated) lesions in the upper part of the stomach (Figure 2). Tumor locates predominantly in the non-antrum part of the stomach [19]. Because gastric cancer related to Helicobacter pylori (Hp), a causative agent of chronic gastritis, intestinal metaplasia, and cancer, locates predominantly in the antrum, these pathogens have been thought to cause gastric cancer by independent mechanisms [19]. Gastritis related to $\mathrm{Hp}$ frequently starts in the antrum. However, Yanai et al. reported that EBVaGC are frequently located near the mucosal atrophic border, where mild to moderate chronic atrophic gastritis (CAG) is common [24]. They also showed frequent detection of both EBV and $\mathrm{Hp}$ at the mucosa with moderate CAG, where inflammatory cell infiltration is abundant, and not at the mucosa with marked CAG, where inflammatory cell infiltration is scarce $[25]$.

Figure 2. Endoscopic image of an early EBVaGC in the upper gastric body. The tumor shows protruded shape probably because of the abundant lymphocyte infiltration.

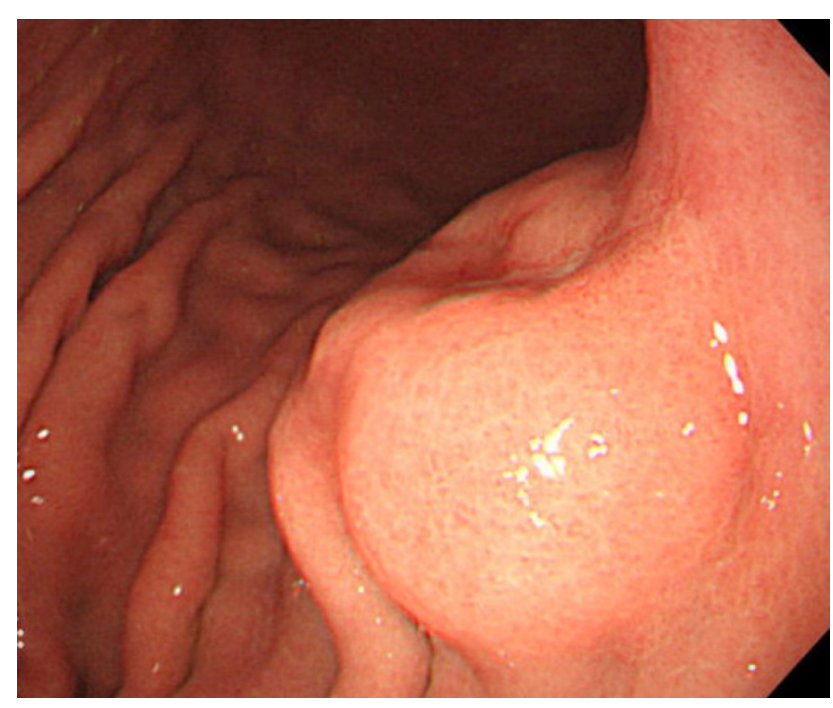

\section{Route of Epithelial Infection}

EBV infects human B lymphocytes and epithelial cells via different entry mechanisms. In case of B cells, the major outer envelope glycoprotein, gp350/220, is responsible for attachment of the virus with high affinity to CD21 or the human complement receptor type 2 (CR2) on B cell surface [26-29]. EBV is subsequently internalized into the cells via endocytic pathway. Fusion with viral envelope and endosomal membrane of B cells is triggered by the interaction of a second envelope glycoprotein, gp42, with HLA class II [30], and is thereafter mediated by the core fusion complex, gH/gL/gp42 $[31,32]$. 
In contrast, the mechanism by which EBV infects human epithelial cells remains unclear. Human epithelial cells are CD21-negative or express CD21 at low level in some epithelial cells in culture and highly resistant to cell-free EBV infection [33,34]. At least three models have been proposed as mechanisms for the EBV attachment to epithelial cells independent of CD21. First, it has been demonstrated that EBV virions coated with immunoglobulin A (IgA) specific to gp350/220 can bind efficiently to the polymeric IgA receptor [35]. Polymeric IgA is commonly present in human saliva and binds to the secretory component (SC) protein, which is a transmembrane protein expressing on the basolateral surfaces of polarized epithelial cells.A complex of EBV/IgA/SC is internalized into epithelial cells via endocytic pathway. This may be relevant to infection through the basolateral surface of an epithelial cell, which presumably resembles the physiological environment that the virus encounters in vivo [36]. Second, a complex of $\mathrm{gH}$ and $\mathrm{gL}$ was proposed to serve as epithelial ligands in the absence of CD21. EBV derived from B cells binds with high affinity to CD21-negative epithelial cells, but recombinant viruses lacking $\mathrm{gH} / \mathrm{gL}$ lose this ability [31,32], suggesting that there is an epithelial cell-specific receptor for $\mathrm{gH} / \mathrm{gL}$ that serves in attachment of EBV. It has been also shown that the direct interaction between $\mathrm{gH} / \mathrm{gL}$ and the integrins $\alpha \mathrm{V} \beta 6$ and $\alpha \mathrm{V} \beta 8$ can provide the trigger for fusion of EBV and plasma membrane of epithelial cells [37]. Finally, an interaction between an EBVencoded membrane protein, BMRF2, and integrins on polarized epithelial cells has been proposed as a model for EBV attachment to the cell surface [38]. The tripeptide Arg-Gly-Asp (RGD) motif in the BMRF2 molecule is presented as a ligand for $\beta 1, \alpha 5, \alpha 3$, and $\alpha \mathrm{V}$ integrins [39,40]. However, BMRF2 is not required for cell-to-cell fusion [41,42] and apparently very few BMRF2 molecules exist in the virion [43]. It remains unclear whether the interaction of BMRF2 with integrins is primarily responsible for attachment and/or post-attachment events.

Interestingly, EBV virions released from B cells are deficient in gp42 which renders them more efficient to infect epithelial cells, but less efficient to infect B cells $[44,45]$. In contrast, EBV released from infected epithelial cells possesses gp42 and efficiently infects B cells [44]. This change in cell type tropism for EBV infection suggests that EBV shuttles between epithelial cells and B cells in the host during infection cycle. This observation supports a model that pharyngeal epithelial cells are in lytic EBV infection and shed infectious EBV particles for transmission.

The fusion of EBV envelope with the plasma membrane of epithelial cells requires a trigger $\mathrm{gH} / \mathrm{gL}$ complex [36,45-49]. The fusion of EBV with an epithelial cell is likely triggered by a direct interaction between $\mathrm{gH} / \mathrm{gL}$ and unknown epithelial cell surface molecules, which might be the identical proteins that can serve as attachment receptors in the absence of CD21 [50]. 
Figure 3. Cell-to-cell contact-mediated EBV transmission to epithelial cells. In cell-free infection, EBV preferentially infects B cells using CD21 receptor. EBV also infects CD21negative epithelial cells as part of its normal life cycle, however much less efficiently. EBV transfer mediated by cell-to-cell contact with B cells increases the infection efficiency 1,000 to 10,000-fold compared with cell-free virus infection.

\section{Cell-free EBV Infection}

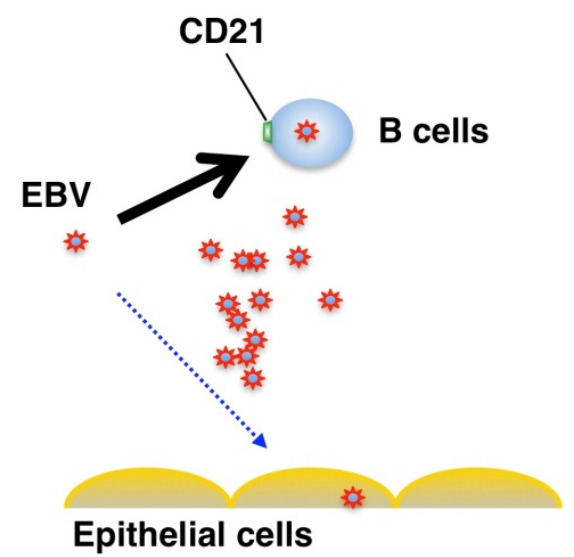

\section{Cell-to-cell contact- mediated EBV Infection}

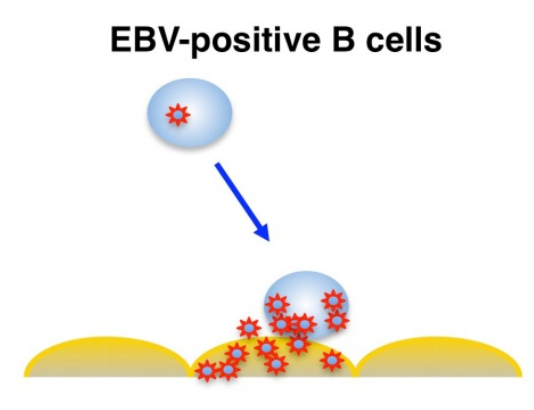

Infection efficiency: $\quad 1<1,000$ to 10,000

Several lines of evidence indicate that EBV infection into epithelial cells is mainly mediated by cell-to-cell contact [34,51-55]. The rate of EBV infection in epithelial cells is $10^{3}$-fold higher by coculturing with EBV-positive B cells than by cell-free infection [34,51,55]. Moreover, most EBV virions are retained on cell surfaces after binding to primary B cells and transferred to epithelial cells, resulting in the $10^{3}$ to $10^{4}$-fold increase of infection compared with cell-free virus infection [53,54].All these studies support a model that EBV-infected B cells migrating into the epithelial stroma or intraepithelial space contribute to the efficient EBV transmission into epithelium via cell-to-cell contact (Figure 3). The detailed molecular mechanisms of cell-to-cell EBV transmission remain unclear. Shannon-Lowe et al. showed that EBV virions loaded on the surface of primary B cells facilitate the formation of a virological synapse (VS)-like intercellular conjugation between B cells and co-cultured epithelial cells $[53,54]$. The VS is a tight adhesive junction across which virus can be efficiently transferred from virus-infected cells to non-infected target cells without cell-cell fusion [56].An important role of an EBV glycoprotein, BMRF2 in the cell-to-cell spread of EBV in polarized oral epithelial cells has been proposed $[39,40]$. The mucosa of oropharyngeal and nasopharyngeal regions are known to be heavily filtrated by lymphocytes, suggesting that cell-free virus in the saliva could first bind to the surface of B cells and then efficiently transfer to pharyngeal epithelial cells through a cellular conjugate between B cells and epithelial cells.

The detailed molecular mechanism by which EBV infects epithelial cells still remains unclear. Some key factors involved in viral attachment, membrane fusion, and cell-to-cell contact-mediated viral transmission, have been identified [48,49]. However, no cellular receptors for EBV infection have yet been identified on epithelial cells.Also very little insights have been provided for a conceptual understanding of viral entry mechanism into epithelial cells. Further investigations are still required. 


\section{Viral Genes and Carcinogenesis}

\subsection{Models of EBV infection of gastric epithelial cells}

EBV infects both B lymphocytes and epithelial cells, since the virus is discovered in BL cells, HL cells, NPC cells, and EBVaGC cells. Experimental EBV infection to B cells is very efficient, since EBV uses high affinity receptor, CD21 for its entry [16]. However, epithelial cells are CD21-negative and infection of epithelial cells could not be achieved for a long time, exceptionally when CD21 expression was overcome by gene transfer [33,57].

We have clearly proved direct infection of human gastric epithelial cells by EBV [50]. The infection was achieved by using a recombinant EBV with a selectable marker gene [58,59], but without any operations, such as introduction of the CD21 gene. In our study, epithelial cells were negative for CD21 and the infection was not blocked by anti-CD21 monoclonal antibody [50]. We have next showed that efficient transfer of EBV to epithelial cells by mixed culture with recombinant EBV producing B cells [34]. Other than experimentally EBV-infected cells, SNU-719 cell [60] and KT cell [61] are few cells retaining the same clonal EBV genome and EBV gene expression pattern of latency I as the original tumor biopsy. EBV-harboring epithelial cells are difficult to propagate in vitro and in animal models.

\subsection{Growth promoting effects of $E B V$}

The KT cell is a good in vivo model of EBVaGC and expresses high IL-1ß compared with EBVnegative gastric tumor cells [62]. Primary cell cultures from healthy gastric mucosal biopsies were infected with recombinant EBV [63]. The established cells expressed Qp-driven EBNA 1, EBER, BART, and LMP2A, similar to EBVaGC. The EBV-positive clones showed rapid proliferation and p53 overexpression, and exhibited anchorage independence in colony formation assay.

Growth promotion by EBV infection was also observed in EBV-infected NU-GC-3 cells through secretion of insulin-like growth factor (IGF)-1 as an autocrine growth factor [64]. It has been shown that EBERs play an oncogenic role by inhibition of apoptosis [65,66] and IGF-1 induction [67]. The oncogenic role of other genes, such as BARF1 [68] and LMP2A [69] has been reported.A recent report showed that EBV infection affected miRNA expression [70]. While no consensus exits as to the exact mechanism by which EBV promotes EBVaGC, the establishment of EBVaGC cell lines and the development of an in vitro model represent significant progress towards this goal.

\section{Virus and Host Interactions at Molecular Level}

\subsection{DNA Hypermethylation in EBV and Host Genomes}

A number of $\mathrm{CpG}$ islands in the promoter region of an tumor suppressor gene have been methylated in cancer cells than in normal cells [71]. Expression of many genes, such as p16 and $R U N X 3$, is suppressed in stomach cancer owing to promoter methylation [72,73]. Promoter hypermethylation is especially frequent in EBVaGC [74-76]. Methylation of promoter region in APC, p16, MINT1, MLH1, 
TP73, and HOXA10 [14,77,78] has been specifically observed in EBVaGC (Table 1).A large-scale analysis revealed that $C X X C 4, T I M P 2$, and $P L X N D 1$ are specifically methylated in EBVaGC [79]. Down regulation of $\mathrm{CXXC4}$, a suppressor of the Wnt pathway, promotes tumor cell proliferation and invasiveness [80]. Down regulation of TIMP2, a suppressor of metalloproteinase, inhibits tumor cell metastasis [81]. Methylation of similar genes has been reported in cancers associated with hepatitis $\mathrm{B}$ or $\mathrm{C}$ infection $[82,83]$, suggesting that a common mechanism may underlie the formation of infectionassociated cancers.

Table 1. DNA hypermethylation in EBVaGC.

\begin{tabular}{|lll|}
\hline Name & Function & Reference \\
\hline$A P C$ & Tumor suppressor, regulate B-catenin signal & 14 \\
\hline$p 16, p 14$ & Tumor suppressor, regulate cell cycle & 14,77 \\
\hline TP73 & Tumor suppressor, regulate apoptosis & 77,78 \\
\hline CXXC4 & Suppressor of Wnt signal & 79 \\
\hline TIMP2 & Inhibitor of metalloproteinase & 79 \\
\hline
\end{tabular}

However, the precise molecular mechanism of host DNA methylation during the early stage of EBV infection of the gastric epithelium is not fully understood. It is reported that LMP2A induces the phosphorylation of STAT3, which activates DNA methyltransferase 1 (DNMT1) transcription and causes PTEN expression loss through CpG island methylation of the PTEN promoter [69].Although LMP2A is expressed in substantial cases of EBVaGC [84], EBVaGC patients are usually negative for LMP2A antibody [85]. Constitutive overexpression of DNMT1 has been observed in EBV-infected gastric epithelial cells that do not express LMP2A significantly [69]. Further investigations using EBV mutants of LMP2A [86] may uncover its precise molecular mechanism.

\section{2. miRNA and Carcinogenesis}

miRNAs are endogenous 18 - 25 nt RNAs and play important gene-regulatory roles in eukaryotic cells via posttranscriptional repression of gene expression. miRNA targets 3 '-untranslated region (UTR) elements of mRNA and mediates mRNA decay through degradation of polyA (RNA silencing: RNAi) [87]. Different expression patterns of miRNA from normal tissues were expected in cancer. Several miRNAs and non-coding RNAs have been found to have links with some types of cancer and are referred as "oncomirs". This is because miRNAs have a role as oncogenes when they target tumor suppressor genes. On the other hand, miRNAs are tumor suppressors when they target oncogenes [88].

A clonal EBV infection has been found in EBV-associated epithelial tumors, such as NPC and EBVaGC [9,89]. EBV encodes a large number of miRNAs [90]. Up to 25 pre-miRNAs are encoded in the BHRF1 and BART regions of the genome, which result in four mature BHRF1 miRNAs and 40 BART miRNAs [91].A prototypic EBV strain B95-8 is known to have $11 \mathrm{kbp}$ deletion in BART region. However, B95-8 virus can be produced in large amount and possesses prominent B cell transformation ability. Moreover, a recombinant virus lacking entire region of BART region was still 
able to infect and transform B cells [92]. These findings indicate that BART transcripts are not required for $\mathrm{B}$ cell transformation and neglected the importance of BART for a long period. Cai et al. identified 13 BART miRNAs in the region of B95-8 deletion [91].

Table 2. EBV-derived miRNAs and their target genes.

\begin{tabular}{|lll|}
\hline Name & Target & Reference \\
BHRF1-1 & GUF1, SCRN1 & 101 \\
\hline miR-BART1 & LMP1 (EBV), CLEC2D, LY75, SP100, & 93,101 \\
miR-BART2 & BALF5 (EBV) & 94 \\
miR-BART3 & DICER1, MICB & 101 \\
miR-BART5 & PUMA, LMP1 (EBV) & 96,100 \\
miR-BART6 & DICER1 & 97 \\
miR-BART10 & BHRF1 (EBV) & 100 \\
miR-BART13 & CAPRIN2 & 100 \\
miR-BART17 & LMP1 (EBV) & 93 \\
miR-BART19 & LMP1 (EBV) & 100 \\
\hline$m i R-B A R T 22$ & LMP2A (EBV) & 95 \\
\hline BARTs & BIM & 98 \\
\hline
\end{tabular}

EBV-encoded BART miRNAs target the 3'-UTRs of viral genes, such as LMP1, BALF5, and LMP2A genes, and negatively regulate expression of these viral genes [93-95]. On the other hand, EBV miRNAs repress cellular proteins, which include p53 up-regulated modulator of apoptosis (PUMA), DICER1, and BIM [96-98] (Table 2). Preservability of the 3'-UTR domain of the target gene between species is a common feature of mammalian miRNA. However, since EBV preferentially infects humans, some EBV miRNAs characteristically target only human gene and not genes for other mammals. EBV miRNAs have another characteristic feature, some of which binding motifs are found only on EBV genome and not preserved on other viral genomes [97,99]. In order to identify EBV miRNA targets, a transcriptome-wide identification of miRNA binding sites has been performed between EBV-negative and EBV-positive cell lines [99-101].

Biological significance of viral miRNA in EBV-infected cells was searched using EBV recombinants. In these recombinants, mutations were systematically introduced in EBV's precursor miRNA transcripts to prevent their subsequent processing into mature viral miRNAs. Phenotypic analyses of miRNA mutants revealed that the viral miRNAs contribute to EBV-associated cellular transformation rather than regulation of viral lytic replication [102].

There are two complicated stories in EBV-infected cells. One is that expression of viral latent genes induces cellular miRNAs. Viral LMP1 induces human miR-146a and miR-155 expression [103105].And excessive miR-155 expression is known to form B lymphoma [106]. Two, infection of EBV conversely suppresses entire host cell miRNA expression [70,107]. Since down-regulation of the cellular microRNA family miR-200 causes epithelial-mesenchymal transition (EMT), this phenomenon must be an important step in the process of malignant transformation of both EBVaGC 
and nasopharyngeal carcinoma cells. The precise mechanism for dysregulation of host miRNA by EBV infection needs to be clarified. It is known that low expression level of miRNA processing enzymes, DICER1 and DROSHA, is well correlated with tumor progression in many cancers [108]. We have shown that the expression level of human DICER1 is also lower in EBV-infected cells than in noninfected cells [97,101]. These findings suggest that progression of EBV-associated tumor is possibly regulated by EBV through regulation of viral and host miRNA expression. However, most of the studies presented in this section are performed using BL cells. Further study using EBV positive gastric epithelial cells is required.

\section{Diagnosis and Treatment of EBV-associated GC}

\subsection{Procedure}

EBER1-ISH is a most sensitive method to identify EBV infection.Application of EBER1-ISH to gastric mucosal biopsy samples from patients who have undergone upper gastrointestinal endoscopy is very useful to make diagnosis of EBVaGC before treatment. Patients with EBVaGC had elevated serum antibodies against EBV early antigen and EBV capsid antigen. However, EBNA1 antibody titers did not show significant difference between patients and healthy counterparts [9].

Yanai et al. examined 124 gastric carcinomas from 117 patients using EBER1-ISH.Among them, twelve tumors (9.7\%) were identified as EBV associated [109]. An interesting feature of EBVaGC is its predominance in the non-antrum part of the stomach (Figure 4A). EBVaGC appears as a superficial depressed- or ulcerated-lesion in the upper part of the stomach. Histology of EBVaGC is mainly diffuse-type carcinoma rich in lymphocyte infiltration (gastric carcinoma with lymphoid stroma). Endoscopic ultrasonography revealed a hypoechoic mass in the third layer, reflecting submucosal nodules [110].

Figure 4. EBVaGC by site in the stomach.A. Distribution of EBVaGC. EBV prevalence was more frequent in the cardia and middle stomach than in the antrum, where over half of EBVnegative gastric cancers were located. B. EBV involvement in remnant cancer by site. Note that frequency of EBV infection in the non remnant cardiac cancer was $10.5 \%$ [22].
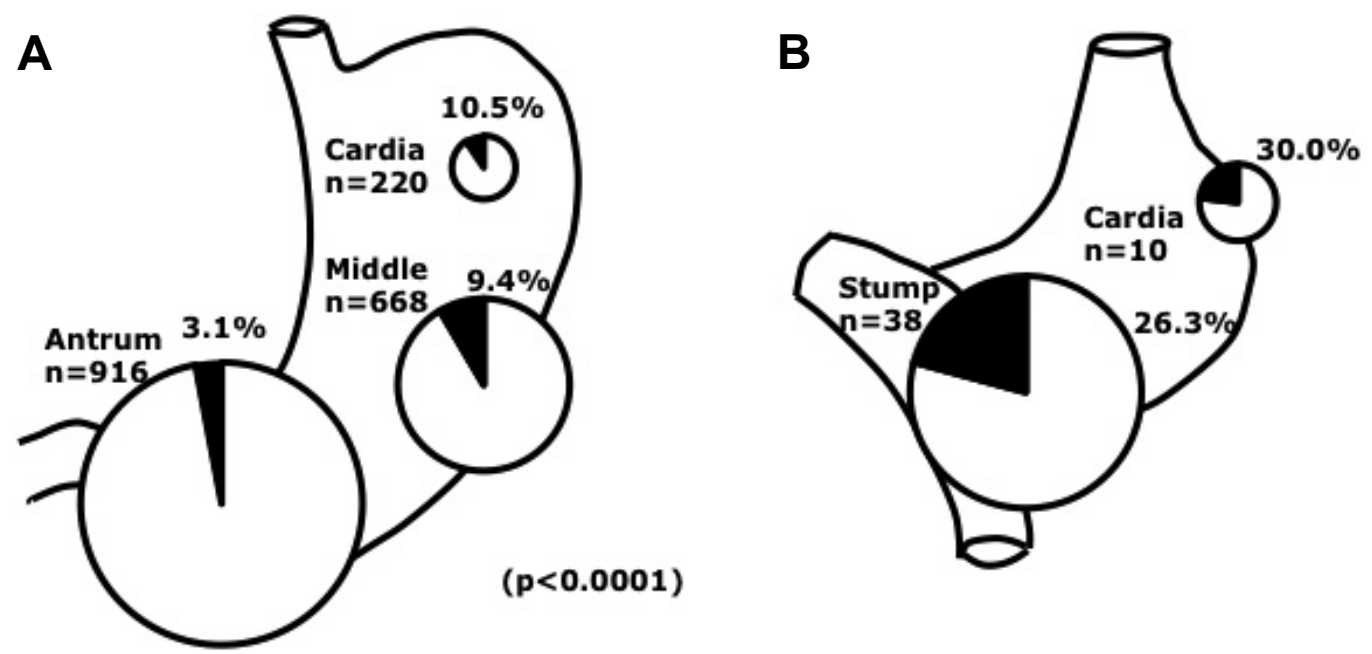
Gastric remnant cancer (gastric stump cancer) after distal gastric resection for benign disease, such as refractory gastric or duodenal ulcer disease or recurrent ulcer with gastric outlet obstruction, remains a substantial clinical concern, because the incidence of remnant cancer is still increasing (Figure 4B) [111].A high prevalence of EBV involvement (25 to 41.2\%) in gastric remnant carcinoma has been reported. High cell proliferation activity in the epithelium has been reported. The reflux of bile and pancreatic juice is considered to cause regenerative atypia and cell proliferation in epithelial cells [112].Atrophic change of remnant gastritis in Billroth-II anastomoses was associated with EBVpositive gastric remnant carcinoma with high incidence [113].

\subsection{Prognosis}

To date there is no specific therapeutic method for EBVaGC. Since the frequency of undifferentiated type of cancer is high in EBVaGC, most of the tumor is surgically resected. CpG island methylation of the promoters of various tumor-related genes plays important roles in the development and progression of gastric cancer [16]. Statistical analysis showed that promoter hypermethylation is more frequently observed in EBVaGC than in EBV-uninfected gastric carcinoma [69,74-76]. Medical treatment with a demethylation agent, which induces lytic EBV infection in latently EBV infected cells, may lead to a lysis of cancer cells. This approach could be applied to the medical treatment of EBVaGC, since methylation of the tumor suppressor gene is also a key abnormality in EBVaGC [12,114,115].

Most of the previous reports did not observe any prognostic difference between EBV-positive and negative gastric cancer [21]. However, early EBVaGC has the low frequency of lymph node metastasis even in submucosal type. Partial medical treatment, such as endoscopic treatment, can be adapted to such a case. The authors have experienced a case of early EBVaGC with submucosal invasion, in which palliative endoscopic treatment was performed. Recurrence was not observed in this case for more than four years [116].A clinicopathological study in the Netherlands mentioned that EBVaGC accompanied lymph node metastasis in significantly lower frequency than EBV-negative stomach cancer. In the study, EBVaGC cases showed a better prognosis than negative cases [117].

\section{Conclusion}

Considerable studies suggest that EBV contributes to cell proliferation and survival, and may directly contribute to the development of EBVaGC through these effects. EBV affects multiple host proteins and pathways that normally promote apoptosis and regulate cell proliferation. However, the underlining molecular mechanisms of these effects are complex and certainly affecting each other.

In another aspect, inflammation of the stomach will recruit EBV-infected B-lymphocytes in the vicinity of gastric epithelia and may increase the frequency of EBV infection of epithelia. Differences in individual inflammatory response by either genetic and/or environmental effect, such as a predisposing loss of ARID1A in epithelial cells before EBV infection [118] or single nucleotide polymorphisms of promoter region of interleukin-10 and/or tumor necrosis factor- $\alpha$ [119], possibly affect the oncogenic pathway to EBVaGC. 


\section{Acknowledgments}

This study was supported by a Grant-in-Aid for Scientific Research from the Ministry of Education, Culture, Science and Technology of Japan (no. 23590534 to H.Y.) and by a Grant for Joint Research Program of the Institute for Genetic Medicine, Hokkaido University (to H.Y.). The authors are indebted to Prof. Kenzo Takada and Dr. Hideo Yanai for their continual support. The authors would like to show sincere gratitude to Ms. Eri Kawanishi for critical reading of the manuscript.

\section{Conflict of Interests}

The authors declare no financial or commercial conflict of interest.

\section{References}

1. zur Hausen, H.; Schulte-Holthausen, H.; Klein, G.; Henle, W.; Henle, G.; Clifford, P.; Santesson, L. EBV DNA in biopsies of Burkitt tumours and anaplastic carcinomas of the nasopharynx. Nature 1970, 228, 1056-1058.

2. Young, L.S.; Murray, P.G. Epstein-Barr virus and oncogenesis: from latent genes to tumours. Oncogene 2003, 22, 5108-5121.

3. Burke, A. P.; Yen, T. S.; Shekitka, K. M.; Sobin, L. H. Lymphoepithelial carcinoma of the stomach with Epstein-Barr virus demonstrated by polymerase chain reaction. Modern Pathol. 1990, 3, 377-380.

4. Shibata, D.; Weiss, L.M. Epstein-Barr virus-associated gastric adenocarcinoma.Am. J. Pathol. 1992, 140, 769-774.

5. Tokunaga, M.; Land, C.E.; Uemura, Y.; Tokudome, T.; Tanaka, S.; Sato, E. Epstein-Barr virus in gastric carcinoma.Am. J. Pathol. 1993, 143, 1250-1254.

6. Takada, K. Epstein-Barr virus and gastric carcinoma. Mol. Pathol. 2000, 53, 255-261.

7. Young, L.S.; Rickinson, A.B. Epstein-Barr virus: 40 years on. Nat. Rev. Cancer 2004, 4, 757768.

8. Fukayama, M.; Hayashi, Y.; Iwasaki, Y.; Chong, J.; Ooba, T.; Takizawa, T.; Koike, M.; Mizutani, S.; Miyaki, M.; Hirai, K. Epstein-Barr virus-associated gastric carcinoma and Epstein-Barr virus infection of the stomach. Lab. Invest. 1994, 71, 73-81.

9. Imai, S.; Koizumi, S.; Sugiura, M.; Tokunaga, M.; Uemura, Y.; Yamamoto, N.; Tanaka, S.; Sato, E.; Osato, T. Gastric carcinoma: monoclonal epithelial malignant cells expressing Epstein-Barr virus latent infection protein. Proc. Natl.Acad. Sci. U. S.A. 1994, 91, 9131-9135.

10. Rickinson, A.B.; Kieff, E. Epstein-Barr virus. In Fields Vilorogy, 5th ed.; Fields, B.N., Knipe, D.M., Howley, P.M., Ed.; Lippincott-Williams \& Wilkins, Philadelphia, PA, USA, 2007; Volume 2, pp. 2655-2700.

11. Robertson, K.D.; Manns, A.; Swinnen, L.J.; Zong, J.C.; Gulley, M.L.; Ambinder, R.F. CpG methylation of the major Epstein-Barr virus latency promoter in Burkitt's lymphoma and Hodgkin's disease. Blood 1996, 88, 3129-3136.

12. Fukayama, M. Epstein-Barr virus and gastric carcinoma. Pathol. Int. 2010, 60, 337-350. 
13. Chong, J.M.; Sakuma, K.; Sudo, M.; Ushiku, T.; Uozaki, H.; Shibahara, J.; Nagai, H.; Funata, N.; Taniguchi, H.; Aburatani, H.; Fukayama, M. Global and non-random CpG-island methylation in gastric carcinoma associated with Epstein-Barr virus. Cancer Sci. 2003, 94, 7680 .

14. Kang, G.H.; Lee, S.; Kim, W.H.; Lee, H.W.; Kim, J.C.; Rhyu, M.G.; Ro, J.Y. Epstein-Barr virus-positive gastric carcinoma demonstrates frequent aberrant methylation of multiple genes and constitutes $\mathrm{CpG}$ island methylator phenotype-positive gastric carcinoma.Am. J. Pathol. 2002, 160, 787-794.

15. Vo, Q.N.; Geradts, J.; Gulley, M.L.; Boudreau, D.A.; Bravo, J.C.; Schneider, B.G. Epstein-Barr virus in gastric adenocarcinomas: association with ethnicity and CDKN2A promoter methylation. J. Clin. Pathol. 2002, 55, 669-675.

16. Feinberg, A.P.; Tycko, B. The history of cancer epigenetics. Nat. Rev. Cancer 2004, 4, 143-153.

17. Ramalingam, D.; Kieffer-Kwon, P.; Ziegelbauer, J.M. Emerging themes from EBV and KSHV microRNA targets. Viruses 2012, 4, 1687-1710.

18. Lee, J.H.; Kim, S.H.; Han, S.H.; An, J.S.; Lee, E.S.; Kim, Y.S. Clinicopathological and molecular characteristics of Epstein-Barr virus-associated gastric carcinoma: a meta-analysis. $J$. Gastroenterol. Hepatol. 2009, 24, 354-365.

19. Akiba, S.; Koriyama, C.; Herrera-Goepfert, R.; Eizuru, Y. Epstein-Barr virus associated gastric carcinoma: epidemiological and clinicopathological features. Cancer Sci. 2008, 99, 195-201.

20. Koriyama, C.; Akiba, S.; Minakami, Y.; Eizuru, Y. Environmental factors related to Epstein-Barr virus-associated gastric cancer in Japan. J. Exp. Clin. Cancer Res. 2005, 24, 547-553.

21. Camargo, M.C.; Murphy, G.; Koriyama, C.; Pfeiffer, R.M.; Kim, W.H.; Herrera-Goepfert, R.; Corvalan, A.H.; Carrascal, E.; Abdirad, A.; Anwar, M.; Hao, Z.; Kattoor, J.; YoshiwaraWakabayashi, E.; Eizuru, Y.; Rabkin, C.S.; Akiba, S. Determinants of Epstein-Barr viruspositive gastric cancer: An international pooled analysis. Br. J. Cancer 2011, 105, 38-43.

22. Tashiro, Y.; Arikawa, J.; Itho, T.; Tokunaga, M. Clinico-pathological findings of Epstein-Barr virus-related gastric cancer. In Epstein-Barr Virus and Human Cancer (Gann Monograph on Cancer Research, No 45); Osato, T., Takada, K., Tokunaga, M., Eds.; S. Karger Ag, Barsel, Switzerland, 1998; pp. 87-97.

23. Tokunaga, M.; Uemura, Y.; Tokudome, T.; Ishidate, T.; Masuda, H.; Okazaki, E.; Kaneko, K.; Naoe, S.; Ito, M.; Okamura, A.; Shimada, A.; Sato, E.; Land, C.E. Epstein-Barr virus related gastric cancer in Japan: A molecular patho-epidemiological study.Acta. Pathol. Jpn. 1993, 43, 574-581.

24. Yanai, H.; Murakami, T.; Yoshiyama, H.; Takeuchi, H.; Nishikawa, J.; Nakamura, H.; Okita, K.; Miura, O.; Shimizu, N.; Takada, K. Epstein-Barr virus-associated gastric carcinoma and atrophic gastritis. J. Clin. Gastroenterol. 1999, 29, 39-43.

25. Hirano, A.; Yanai, H.; Shimizu, N.; Okamoto, T.; Matsubara, Y.; Yamamoto, K.; Okita, K. Evaluation of Epstein-Barr virus DNA load in gastric mucosa with chronic atrophic gastritis using a real-time quantitative PCR assay. Int. J. Gastrointest. Cancer. 2003, 34, 87-94.

26. Fingeroth, J.D.; Weis, J.J.; Tedder, T. F.; Strominger, J.L.; Biro, P.A.; Fearon, D.T. Epstein-Barr virus receptor of human B lymphocytes is the C3d receptor CR2. Proc. Natl.Acad. Sci. U. S.A. 1984, 81, 4510-4514. 
27. Nemerow, G.R.; Mold, C.; Schwend, V.K.; Tollefson, V.; Cooper, N.R. Identification of gp350 as the viral glycoprotein mediating attachment of Epstein-Barr virus (EBV) to the EBV/C3d receptor of B cells: sequence homology of gp350 and C3 complement fragment C3d. J. Virol. 1987, 61, 1416-1420.

28. Tanner, J.; Weis, J.; Fearon, D.; Whang, Y.; Kieff, E. Epstein-Barr virus gp350/220 binding to the B lymphocyte C3d receptor mediates adsorption, capping, and endocytosis. Cell 1987, 50, 203-213.

29. Tanner, J.; Whang, Y.; Sample, J.; Sears, A.; Kieff, E. Soluble gp350/220 and deletion mutant glycoproteins block Epstein-Barr virus adsorption to lymphocytes. J. Virol. 1988, 62, 44524464.

30. Li, Q.; Spriggs, M.K.; Kovats, S.; Turk, S.M.; Comeau, M.R.; Nepom, B.; Hutt-Fletcher, L.M. Epstein-Barr virus uses HLA class II as a cofactor for infection of B lymphocytes. J. Virol. 1997, $71,4657-4662$.

31. Molesworth, S.J.; Lake, C.M.; Borza, C.M.; Turk, S.M.; Hutt-Fletcher, L.M. Epstein-Barr virus $\mathrm{gH}$ is essential for penetration of $\mathrm{B}$ cells but also plays a role in attachment of virus to epithelial cells. J. Virol. 2000, 74, 6324-6332.

32. Oda, T.; Imai, S.; Chiba, S.; Takada, K. Epstein-Barr virus lacking glycoprotein gp85 cannot infect B cells and epithelial cells. Virology 2000, 276, 52-58.

33. Fingeroth, J.D.; Diamond, M.E.; Sage, D.R.; Hayman, J.; Yates J.L. CD21-Dependent infection of an epithelial cell line, 293, by Epstein-Barr virus. J. Virol. 1999, 73, 2115-2125.

34. Imai, S.; Nishikawa, J.; Takada, K. Cell-to-cell contact as an efficient mode of Epstein-Barr virus infection of diverse human epithelial cells. J. Virol. 1998, 72, 4371-4378.

35. Sixbey, J.W.; Yao, Q.Y. Immunoglobulin A-induced shift of Epstein-Barr virus tissue tropism. Science 1992, 255, 1578-1580.

36. Gan, Y.J.; Chodosh, J.; Morgan, A.; Sixbey, J.W. Epithelial cell polarization is a determinant in the infectious outcome of immunoglobulin A-mediated entry by Epstein-Barr virus. J. Virol. 1997, 71, 519-526.

37. Chesnokova, L.S.; Nishimura, S.L.; Hutt-Fletcher, L.M. Fusion of epithelial cells by epsteinbarr virus proteins is triggered by binding of viral glycoproteins ghgl to integrins alphavbeta6 or alphavbeta8. Proc. Natl.Acad. Sci. U. S.A. 2009, 106, 20464-20469.

38. Tugizov, S.M.; Berline, J.W.; Palefsky, J.M. Epstein-Barr virus infection of polarized tongue and nasopharyngeal epithelial cells. Nat. Med. 2003, 9, 307-314.

39. Xiao, J.; Palefsky, J.M.; Herrera, R.; Berline, J.; Tugizov, S. M. The Epstein-Barr virus BMRF-2 protein facilitates virus attachment to oral epithelial cells. Virology 2008, 370, 430-442.

40. Xiao, J.; Palefsky, J.M.; Herrera, R.; Tugizov, S.M. Characterization of the Epstein-Barr virus glycoprotein BMRF-2. Virology 2007, 359, 382-396.

41. Haan, K.M.; Lee, S.K.; Longnecker, R. Different functional domains in the cytoplasmic tail of glycoprotein B are involved in Epstein-Barr virus-induced membrane fusion. Virology 2001, 290, 106-114.

42. McShane, M.P.; Longnecker, R. Cell-surface expression of a mutated Epstein-Barr virus glycoprotein B allows fusion independent of other viral proteins. Proc. Natl.Acad. Sci. U. S.A. 2004, 101, 17474-17479. 
43. Johannsen, E.; Luftig, M.; Chase, M.R.; Weicksel, S.; Cahir-McFarland, E.; Illanes, D.; Sarracino, D.; Kieff, E. Proteins of purified Epstein-Barr virus. Proc. Natl.Acad. Sci. U. S.A. 2004, 101, 16286-16291.

44. Borza, C.M.; Hutt-Fletcher, L.M.Alternate replication in B cells and epithelial cells switches tropism of Epstein-Barr virus. Nat. Med. 2002, 8, 594-599.

45. Borza, C.M.; Morgan, A.J.; Turk, S.M.; Hutt-Fletcher, L.M. Use of gHgL for attachment of Epstein-Barr virus to epithelial cells compromises infection. J. Virol. 2004, 78, 5007-5014.

46. Omerovic, J.; Lev, L.; Longnecker, R. The amino terminus of Epstein-Barr virus glycoprotein $\mathrm{gH}$ is important for fusion with epithelial and B cells. J. Virol. 2005, 79, 12408-12415.

47. Wang, X.; Kenyon, W.J.; Li, Q.; Mullberg, J.; Hutt-Fletcher, L.M. Epstein-Barr virus uses different complexes of glycoproteins $\mathrm{gH}$ and $\mathrm{gL}$ to infect B lymphocytes and epithelial cells. $J$. Virol. 1998, 72, 5552-5558.

48. Wu, L.; Borza, C.M.; Hutt-Fletcher, L.M. Mutations of Epstein-Barr virus gH that are differentially able to support fusion with B cells or epithelial cells. J. Virol. 2005, 79, 1092310930.

49. Wu, L.; Hutt-Fletcher, L.M. Point mutations in EBV gH that abrogate or differentially affect B cell and epithelial cell fusion. Virology 2007, 363, 148-155.

50. Yoshiyama, H.; Imai, S.; Shimizu, N.; Takada, K. Epstein-Barr virus infection to human gastric carcinoma cells : Implication of the existence of a new virus receptor different from CD21. $J$. Virol. 1997, 71, 5688-5691.

51. Chang, Y.; Tung, C.H.; Huang, Y.T.; Lu, J.; Chen, J.Y.; Tsai, C.H. Requirement for cell-to-cell contact in Epstein-Barr virus infection of nasopharyngeal carcinoma cells and keratinocytes. $J$. Virol. 1999, 73, 8857-8866.

52. Nanbo, A.; Terada, H.; Kachi, K.; Takada, K.; Matsuda, T. Roles of cell signaling pathways in cell-to-cell contact-mediated Epstein-Barr virus transmission. J. Virol. 2012, 86, 9285-9296.

53. Shannon-Lowe, C.; Rowe, M., Epstein-Barr virus infection of polarized epithelial cells via the basolateral surface by memory B cell-mediated transfer infection. PLoS Pathog. 2011, 7, e1001338.

54. Shannon-Lowe, C.D.; Neuhierl, B.; Baldwin, G.; Rickinson, A.B.; Delecluse, H.J. Resting B cells as a transfer vehicle for Epstein-Barr virus infection of epithelial cells. Proc. Natl.Acad. Sci. U. S.A. 2006, 103, 7065-7070.

55. Speck, P.; Longnecker, R. Infection of breast epithelial cells with Epstein-Barr virus via cell-tocell contact. J. Natl. Cancer Inst. 2000, 92, 1849-1851.

56. Jolly, C.; Sattentau, Q.J. Retroviral spread by induction of virological synapses. Traffic 2004, 5, 643-650.

57. Li, Q. X.; Young, L.S.; Niedobitek, G.; Dawson, C.W.; Birkenbach, M.; Wang, F.; Rickinson, A.B. Epstein-Barr virus infection and replication in a human epithelial cell system. Nature 1992, 356, 347-350.

58. Yoshiyama, H.; Shimizu, N.; Takada, K. Persistent Epstein-Barr virus infection in a human Tcell line : Unique program of latent virus expression. EMBO. J. 1995, 14, 3706-3711.

59. Shimizu, N.; Yoshiyama, H.; Takada, K. Clonal propagation of Epstein-Barr virus (EBV) recombinants in EBV-negative Akata cells. J. Virol. 1996, 70, 7260-7263. 
60. Oh, S.T.; Seo, J.S.; Moon, U.Y.; Kang, K.H.; Shin, D.J.; Yoon, S.K.; Kim, W.H.; Park, J.G.; Lee, S.K. A naturally derived gastric cancer cell line shows latency I Epstein-Barr virus infection closely resembling EBV-associated gastric cancer. Virology 2004, 320, 330-336.

61. Iwasaki, Y.; Chong, J.M.; Hayashi, Y.; Ikeno, R.; Arai, K.; Kitamura, M.; Koike, M.; Hirai, K.; Fukayama, M. Establishment and characterization of a human Epstein-Barr virus-associated gastric carcinoma in SCID mice. J. Virol. 1998, 72, 8321-8326.

62. Chong, J.M.; Sakuma, K.; Sudo, M.; Osawa, T.; Ohara, E.; Uozaki, H.; Shibahara, J.; Kuroiwa, K.; Tominaga, S.; Hippo, Y.; Aburatani, H.; Funata, N.; Fukayama, M. Interleukin1 beta expression in human gastric carcinoma with Epstein-Barr virus infection. J. Virol. 2002, $76,6825-6831$.

63. Nishikawa, J.; Imai, S.; Oda, T.; Kojima, T.; Okita, K.; Takada, K. Epstein-Barr virus promotes epithelial cell growth in the absence of EBNA2 and LMP1 expression. J. Virol. 1999, 73, 12861292.

64. Iwakiri, D.; Eizuru, Y.; Tokunaga, M.; Takada, K. Autocrine growth of Epstein-Barr viruspositive gastric carcinoma cells mediated by an Epstein-Barr virus-encoded small RNA. Cancer Res. 2003, 63, 7062-7067.

65. Komano, J.; Maruo, S.; Kurozumi, K.; Oda, T.; Takada, K. Oncogenic role of Epstein-Barr virus-encoded RNAs in Burkitt's lymphoma cell line Akata. J. Virol. 1999, 73, 9827-9831.

66. Nanbo, A.; Yoshiyama, H.; Takada, K. Epstein-Barr virus-encoded poly(A)- RNA confers resistance to apoptosis mediated through Fas by blocking the PKR pathway in human epithelial intestine 407 cells. J. Virol. 2005, 79, 12280-12285.

67. Iwakiri, D.; Sheen, T.S.; Chen, J.Y.; Huang, D.P.; Takada, K. Epstein-Barr virus-encoded small RNA induces insulin-like growth factor 1 and supports growth of nasopharyngeal carcinomaderived cell lines. Oncogene 2005, 24, 1767-1773.

68. Seto, E.; Yang, L.; Middeldorp, J.; Sheen, T.S.; Chen, J.Y.; Fukayama, M.; Eizuru, Y.; Ooka, T.; Takada, K. Epstein-Barr virus (EBV)-encoded BARF1 gene is expressed in nasopharyngeal carcinoma and EBV-associated gastric carcinoma tissues in the absence of lytic gene expression. J. Med. Virol. 2005, 76, 82-88.

69. Hino, R.; Uozaki, H.; Murakami, N.; Ushiku, T.; Shinozaki, A.; Ishikawa, S.; Morikawa, T.; Nakaya, T.; Sakatani, T.; Takada, K.; Fukayama, M. Activation of DNA methyltransferase 1 by EBV latent membrane protein 2A leads to promoter hypermethylation of PTEN gene in gastric carcinoma. Cancer Res. 2009, 69, 2766-2774.

70. Shinozaki, A.; Sakatani, T.; Ushiku, T.; Hino, R.; Isogai, M.; Ishikawa, S.; Uozaki, H.; Takada, K.; Fukayama, M. Downregulation of microRNA-200 in EBV-associated gastric carcinoma. Cancer Res. 2010, 70, 4719-4727.

71. Herman, J.G. Hypermethylation of tumor suppressor genes in cancer. Semin. Can. Biol. 1999, 9, $359-367$.

72. Li, Q.L.; Ito, K.; Sakakura, C.; Fukamachi, H.; Inoue, K.; Chi, X.Z.; Lee, K.Y.; Nomura, S.; Lee, C.W.; Han, S.B.; Kim, H.M.; Kim, W.J.; Yamamoto, H.; Yamashita, N.; Yano, T.; Ikeda, T.; Itohara, S.; Inazawa, J.; Abe, T.; Hagiwara, A.; Yamagishi, H.; Ooe, A.; Kaneda, A.; Sugimura, T.; Ushijima, T.; Bae, S.C.; Ito, Y. Causal relationship between the loss of RUNX3 expression and gastric cancer. Cell 2002, 109, 113-124. 
73. Kaneda, A.; Kaminishi, M.; Yanagihara, K.; Sugimura, T.; Ushijima, T. Identification of silencing of nine genes in human gastric cancers. Cancer Res. 2002, 62, 6645-6650.

74. Kusano, M.; Toyota, M.; Suzuki, H.; Akino, K.; Aoki, F.; Fujita, M.; Hosokawa, M.; Shinomura, Y.; Imai, K.; Tokino, T. Genetic, epigenetic, and clinicopathologic features of gastric carcinomas with the $\mathrm{CpG}$ island methylator phenotype and an association with Epstein-Barr virus. Cancer 2006, 106, 1467-1479.

75. Chang, M.S.; Uozaki, H.; Chong, J.M.; Ushiku, T.; Sakuma, K.; Ishikawa, S.; Hino, R.; Barua, R.R.; Iwasaki, Y.; Arai, K.; Fujii, H.; Nagai, H.; Fukayama, M. CpG island methylation status in gastric carcinoma with and without infection of Epstein-Barr virus. Clin. Cancer Res. 2006, 12, 2995-3002.

76. Kaneda, A.; Matsusaka, K.; Aburatani, H.; Fukayama, M. Epstein-Barr virus infection as an epigenetic driver of tumorigenesis. Cancer Res. 2012, 72, 3445-50.

77. Ushiku, T.; Chong, J.M.; Uozaki, H.; Hino, R.; Chang, M.S.; Sudo, M.; Rani, B.R.; Sakuma, K.; Nagai, H.; Fukayama, M. p73 gene promoter methylation in Epstein-Barr virus-associated gastric carcinoma. Int. J. Cancer 2007, 120, 60-66.

78. Kang, G.H.; Lee, S.; Cho, N.Y.; Gandamihardja, T.; Long, T.I.; Weisenberger, D.J.; Campan, M.; Laird, P.W. DNA methylation profiles of gastric carcinoma characterized by quantitative DNA methylation analysis. Lab. Invest. 2008, 88, 161-170.

79. Matsusaka, K.; Kaneda, A.; Nagae, G.; Ushiku, T.; Kikuchi, Y.; Hino, R.; Uozaki, H.; Seto, Y.; Takada, K.; Aburatani, H.; Fukayama, M. Classification of Epstein-Barr virus-positive gastric cancers by definition of DNA methylation epigenotypes. Cancer Res. 2011, 71, 7187-7197.

80. Kojima, T.; Shimazui, T.; Hinotsu, S.; Joraku, A.; Oikawa, T.; Kawai, K.; Horie, R.; Suzuki, H.; Nagashima, R.; Yoshikawa, K.; Michiue, T.; Asashima, M.; Akaza, H.; Uchida, K. Decreased expression of CXXC4 promotes a malignant phenotype in renal cell carcinoma by activating Wnt signaling. Oncogene 2009, 28, 297-305.

81. Kawamata, H.; Kawai, K.; Kameyama, S.; Johnson, M.D.; Stetler-Stevenson, W. G.; Oyasu, R. Over-expression of tissue inhibitor of matrix metalloproteinases (TIMP1 and TIMP2) suppresses extravasation of pulmonary metastasis of a rat bladder carcinoma. Int. J. Cancer 1995, 63, 680687.

82. Kanai, Y.; Hui, A. M.; Sun, L.; Ushijima, S.; Sakamoto, M.; Tsuda, H.; Hirohashi, S. DNA hypermethylation at the D17S5 locus and reduced HIC-1 mRNA expression are associated with hepatocarcinogenesis. Hepatology 1999, 29, 703-709.

83. Kondo, Y.; Kanai, Y.; Sakamoto, M.; Mizokami, M.; Ueda, R.; Hirohashi, S. Genetic instability and aberrant DNA methylation in chronic hepatitis and cirrhosis-A comprehensive study of loss of heterozygosity and microsatellite instability at 39 loci and DNA hypermethylation on $8 \mathrm{CpG}$ islands in microdissected specimens from patients with hepatocellular carcinoma. Hepatology 2000, 32, 970-979.

84. Luo, B.; Wang, Y.; Wang, X.F.; Liang, H.; Yan, L.P.; Huang, B.H.; Zhao, P. Expression of Epstein-Barr virus genes in EBV-associated gastric carcinomas. World J. Gastroenterol. 2005, 11, 629-633.

85. Lennette, E.T.; Winberg, G.; Yadav, M.; Enblad, G.; Klein, G.Antibodies to LMP2A/2B in EBVcarrying malignancies. Eur. J. Cancer 1995, 31A, 1875-1878. 
86. Konishi, K.; Maruo, S.; Kato, H.; Takada, K. Role of Epstein-Barr virus-encoded latent membrane protein $2 \mathrm{~A}$ on virus-induced immortalization and virus activation. J. Gen. Virol. 2001, $82,1451-1456$.

87. Bartel, D.P. MicroRNAs: target recognition and regulatory functions. Cell 2009, 136, 215-233.

88. Nana-Sinkam, S.P.; Croce, C. M. Non-coding RNAs in cancer initiation and progression and as novel biomarkers. Mol. Oncol. 2011, 5, 483-491.

89. Raab-Traub, N.; Flynn, K. The structure of the termini of the Epstein-Barr virus as a marker of clonal cellular proliferation. Cell 1986, 47, 883-889.

90. Pfeffer, S.; Zavolan, M.; Grasser, F.A.; Chien, M.; Russo, J.J.; Ju, J.; John, B.; Enright, A.J.; Marks, D.; Sander, C.; Tuschl, T. Identification of virus-encoded microRNAs. Science 2004, 304, 734-736.

91. Cai, X.; Schäfer, A.; Lu, S.; Bilello, J.P.; Desrosiers, R.C.; Edwards, R.; Raab-Traub, N.; Cullen, B.R. Epstein-Barr virus microRNAs are evolutionarily conserved and differentially expressed. PLoS Pathog. 2006, 2, e23.

92. Robertson, E.S.; Tomkinson, B.; Kieff, E. An Epstein-Barr virus with a 58-kilobase-pair deletion that includes BARF0 transforms B lymphocytes in vitro. J. Virol. 1994, 68, 1449-1458.

93. Lo, A.K.; To, K.F.; Lo, K.W.; Lung, R. W.; Hui, J.W.; Liao, G.; Hayward, S.D. Modulation of LMP1 protein expression by EBV-encoded microRNAs. Proc. Natl. Acad. Sci. U. S.A. 2007, 104, 16164-16169.

94. Barth, S.; Pfuhl, T.; Mamiani, A.; Ehses, C.; Roemer, K.; Kremmer, E.; Jaker, C.; Hock, J.; Meister, G.; Grasser, F.A. Epstein-Barr virus-encoded microRNA miR-BART2 down-regulates the viral DNA polymerase BALF5. Nucleic. Acids Res. 2008, 36, 666-675.

95. Lung, R.W.; Tong, J.H.; Sung, Y.M.; Leung, P.S.; Ng, D.C.; Chau, S.L.; Chan, A.W.; Ng, E.K.; Lo, K.W.; To, K.F. Modulation of LMP2A expression by a newly identified Epstein-Barr virusencoded microRNA miR-BART22. Neoplasia. 2009, 11, 1174-1184.

96. Choy, E.Y.; Siu, K.L.; Kok, K.H.; Lung, R.W.; Tsang, C.M.; To, K.F.; Kwong, D.L.; Tsao, S.W.; Jin, D.Y. An Epstein-Barr virus-encoded microRNA targets PUMA to promote host cell survival. J. Exp. Med. 2008, 205, 2551-2560.

97. Iizasa, H.; Wulff, B.E.; Alla, N.R.; Maragkakis, M.; Megraw, M.; Hatzigeorgiou, A.; Iwakiri, D.; Takada, K.; Wiedmer, A.; Showe, L.; Lieberman, P.; Nishikura, K. Editing of Epstein-Barr virus-encoded BART6 microRNAs controls their dicer targeting and consequently affects viral latency. J. Biol. Chem. 2010, 285, 33358-33370.

98. Marquitz, A.R.; Mathur, A.; Nam, C.S.; Raab-Traub, N. The Epstein-Barr Virus BART microRNAs target the pro-apoptotic protein Bim. Virology 2011, 412, 392-400.

99. Gottwein, E.; Corcoran, D.L.; Mukherjee, N.; Skalsky, R.L.; Hafner, M.; Nusbaum, J.D.; Shamulailatpam, P.; Love, C.L.; Dave, S.S.; Tuschl, T.; Ohler, U.; Cullen, B.R. Viral microRNA targetome of KSHV-infected primary effusion lymphoma cell lines. Cell Host Microbe. 2011, $10,515-526$.

100. Riley, K.J.; Rabinowitz, G.S.; Yario, T.A.; Luna, J.M.; Darnell, R.B.; Steitz, J.A. EBV and human microRNAs co-target oncogenic and apoptotic viral and human genes during latency. EMBO J. 2012, 31, 2207-2221. 
101. Skalsky, R.L.; Corcoran, D.L.; Gottwein, E.; Frank, C.L.; Kang, D.; Hafner, M.; Nusbaum, J.D.; Feederle, R.; Delecluse, H.J.; Luftig, M.A.; Tuschl, T.; Ohler, U.; Cullen, B.R. The viral and cellular microRNA targetome in lymphoblastoid cell lines. PLoS Pathog. 2012, 8, e1002484.

102. Seto, E.; Moosmann, A.; Gromminger, S.; Walz, N.; Grundhoff, A.; Hammerschmidt, W. Micro RNAs of Epstein-Barr virus promote cell cycle progression and prevent apoptosis of primary human B cells. PLoS Pathog. 2010, 6, e1001063.

103. Cameron, J.E.; Yin, Q.; Fewell, C.; Lacey, M.; McBride, J.; Wang, X.; Lin, Z.; Schaefer, B.C.; Flemington, E.K. Epstein-Barr virus latent membrane protein 1 induces cellular MicroRNA miR-146a, a modulator of lymphocyte signaling pathways. J. Virol. 2008, 82, 1946-1958.

104. Motsch, N.; Pfuhl, T.; Mrazek, J.; Barth, S.; Grasser, F.A. Epstein-Barr virus-encoded latent membrane protein 1 (LMP1) induces the expression of the cellular microRNA miR-146a. RNA Biol. 2007, 4, 131-137.

105. Gatto, G.; Rossi, A.; Rossi, D.; Kroening, S.; Bonatti, S.; Mallardo, M. Epstein-Barr virus latent membrane protein 1 trans-activates miR-155 transcription through the NF-kappaB pathway. Nucleic Acids Res. 2008, 36, 6608-6619.

106. Costinean, S.; Zanesi, N.; Pekarsky, Y.; Tili, E.; Volinia, S.; Heerema, N.; Croce, C.M. Pre-B cell proliferation and lymphoblastic leukemia/high-grade lymphoma in $\mathrm{E}(\mathrm{mu})$-miR155 transgenic mice. Proc. Natl.Acad. Sci. U. S.A. 2006, 103, 7024-7029.

107. Godshalk, S.E.; Bhaduri-McIntosh, S.; Slack, F.J. Epstein-Barr virus-mediated dysregulation of human microRNA expression. Cell Cycle 2008, 7, 3595-3600.

108. Merritt, W.M.; Lin, Y.G.; Han, L.Y.; Kamat, A.A.; Spannuth, W.A.; Schmandt, R.; Urbauer, D.; Pennacchio, L.A.; Cheng, J.F.; Nick, A.M.; Deavers, M.T.; Mourad-Zeidan, A.; Wang, H.; Mueller, P.; Lenburg, M.E.; Gray, J.W.; Mok, S.; Birrer, M.J.; Lopez-Berestein, G.; Coleman, R.L.; Bar-Eli, M.; Sood, A.K. Dicer, Drosha, and outcomes in patients with ovarian cancer. New Engl. J. Med. 2008, 359, 2641-2650.

109. Yanai, H.; Nishikawa, J.; Mizugaki, Y.; Shimizu, N.; Takada, K.; Matsusaki, K.; Toda, T.; Matsumoto, Y.; Tada, M.; Okita, K. Endoscopic and pathologic features of Epstein-Barr virusassociated gastric carcinoma. Gastrointest. Endosc. 1997, 45, 236-242.

110. Nishikawa, J.; Yanai, H.; Mizugaki, Y.; Takada, K.; Tada, M.; Okita, K. Hypoechoic submucosal nodules: a sign of Epstein-Barr virus-associated early gastric cancer. J. Gastroenterol. Hepatol. 1998, 13, 585-590.

111. Lagergren, J.; Lindam, A.; Mason, R.M. Gastric stump cancer after distal gastrectomy for benign gastric ulcer in a population-based study. Int. J. Cancer 2012, 131, E1048-1052.

112. Yamamoto, N.; Tokunaga, M.; Uemura, Y.; Tanaka, S.; Shirahama, H.; Nakamura, T.; Land, C.E.; Sato, E. Epstein-Barr virus and gastric remnant cancer. Cancer 1994, 74, 805-809.

113. Nishikawa, J.; Yanai, H.; Hirano, A.; Okamoto, T.; Nakamura, H.; Matsusaki, K.; Kawano, T.; Miura, O.; Okita, K. High prevalence of Epstein-Barr virus in gastric remnant carcinoma after Billroth-II reconstruction. Scand. J. Gastroenterol. 2002, 37, 825-829.

114. Feng, W.H.; Hong, G.; Delecluse, H.J.; Kenney, S.C. Lytic induction therapy for Epstein-Barr virus-positive B-cell lymphomas. J. Virol. 2004, 78, 1893-1902.

115. Griffiths, E.A.; Gore, S.D. DNA methyltransferase and histone deacetylase inhibitors in the treatment of myelodysplastic syndromes. Semin. Hematol. 2008, 45, 23-30. 
116. Nishikawa, J.; Saito, M.; Kiyotoki, S.; Hamabe, K.; Okamoto, T.; Yanai, H.; Sakaida, I. EpsteinBarr virus associated gastric carcinoma. (in Japanese) Biotherapy 2010, 24, 429-434.

117. van Beek, J.; zur Hausen, A.; Klein, Kranenbarg, E.; van de Velde, C.J.; Middeldorp, J.M.; van den Brule, A.J.; Meijer, C.J.; Bloemena, E. EBV-positive gastric adenocarcinomas: a distinct clinicopathologic entity with a low frequency of lymph node involvement. J. Clin. Oncol. 2004, 22, 664-670.

118. Abe, H.; Maeda, D.; Hino, R.; Otake, Y.; Isogai, M.; Ushiku, A.S.; Matsusaka, K.; Kunita, A.; Ushiku, T.; Uozaki, H.; Tateishi, Y.; Hishima, T.; Iwasaki, Y.; Ishikawa, S.; Fukayama, M.ARID1A expression loss in gastric cancer: Pathway-dependent roles with and without Epstein-Barr virus infection and microsatellite instability. Virchows Arch. 2012, 461, 367-377.

119. Wu, M.S.; Huang, S.P.; Chang, Y.T.; Shun, C.T.; Chang, M.C.; Lin, M.T.; Wang, H.P.; Lin, J.T. Tumor necrosis factor-alpha and interleukin-10 promoter polymorphisms in Epstein-Barr virusassociated gastric carcinoma. J. Infect. Dis. 2002, 185, 106-109.

(C) 2012 by the authors; licensee MDPI, Basel, Switzerland. This article is an open access article distributed under the terms and conditions of the Creative Commons Attribution license (http://creativecommons.org/licenses/by/3.0/). 